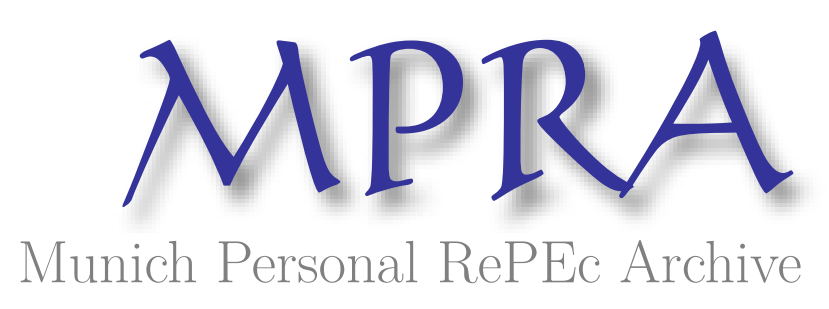

\title{
Long Term Risk Assessment in a Defined Contribution Pension System
}

\author{
Castaneda, Pablo
}

Superintendencia de AFP (Chile)

31 July 2006

Online at https://mpra.ub.uni-muenchen.de/3347/

MPRA Paper No. 3347, posted 29 May 2007 UTC 


\title{
Long Term Risk Assessment in a Defined Contribution Pension System*
}

\author{
Pablo Castañeda ${ }^{\ddagger}$
}

This draft: Abril $2007 \quad$ First draft: July 2006

\begin{abstract}
One of the most important consequences of the Chilean pension reform undertaken in the early 1980s was to transfer a significant portion of the risk associated to the financing of pensions, from the State, to the pension fund participants of the newly established compulsory pension system. This paper is concerned with the risk embedded in the portfolio strategies of pension fund portfolio managers.

We develop an analytic framework that permits to incorporate the behavior of a pension fund manager in the long-term risk assessment of its investment strategy, where the latter is conducted from the point of view of the pension fund participant, who has preferences over his/her final pension. The pension fund manager's problem is cast as a dynamic portfolio choice problem, and its solution is used afterwards to quantify the risk exposure of the pension fund participant.

Our results from a simulation exercise show that the lower is the risk aversion of the participant, the higher is his/her Wealth-at-Risk - defined as the monetary compensation that leaves the participant indifferent with respect to his/her outside option- a result that is due to the fact that the outside option increases relatively more than the benefit derived from the pension provided by the fund manager. The same logic is behind the negative relationship between stock return volatility and pension risk.
\end{abstract}

JEL classification: D81; G11; G18; and H55.

Key words: Dynamic convex risk measure; Pension system, Portfolio selection.

${ }^{*}$ I specially thank Eduardo Walker and Felipe Zurita for their suggestions, the members of the SAFP Research Department, and the participants to the 2006 Meeting of the Chilean Economic Society. The usual caveat applies.

${ }^{+}$The views and conclusions presented in the paper are exclusively those of the author and do not necessarily reflect the position of the Superintendency of Pension Fund Administrators.

¥Boston University (Department of Economics) and Superintendency of PFA (Research Department). Correspondence: Huerfanos 1273, 8th Floor, Santiago 8340382. Chile. Tel. (+56 2) 753-0200. Fax (+56 2) 753-0201. E-mail: <pcastaneda@safp.cl>. 


\section{Introduction}

One of the most important consequences of the Chilean pension reform undertaken at the beginning of the 1980s was to transfer a significant portion of the risk associated to the financing of pensions, from the State - the only sponsor of the public pension system at the time - to the members of the newly established compulsory pension system based on individual accounts. A similar situation -although with a different intensityhas occurred in other Latin-American countries that followed the same path (Argentina, Bolivia, Colombia, Costa Rica, Mexico, Peru, among others). From the perspective of pension fund participants, this risk transfer has been further exacerbated by the fact that under the new regime participants are also required to make investment decisions, by choosing the investment vehicle that best fits their interests, among the different options offered by the private portfolio managers in the market, known as Pension Fund Administrators (PFAs).

From a theoretical standpoint, the potential benefits of the new institutional arrangement, over those of a pay-as-you-go pension system, rely on the assumption that the incentives faced by PFAs allow them to better fulfill the implicit mandate of the pension system's participants (determined by their preferences). In principle, a fully funded pension system operated by private pension fund managers has the potential to provide a better asset allocation. However, the materialization of such a benefit depends crucially on the set of incentives that surrounds PFAs' decisions. In most of the new private pension systems the key incentives influencing the behavior of PFAs come from the regulatory framework. In the case of Chile we can identify at least two such incentives. The first one comes from the explicit mandate contained in the pension law that requires each PFA to manage the pension funds having as its sole objective to obtain an adequate (nominal or real) return, and the second from the so-called minimum return requirement, that establishes a penalty to the PFA if the average return (in the last 36 months) of the pension fund under its management is below the industry average. From these two rules, in addition to the natural interest of the fund manager to not underperform its competitors (which is at the center of most PFAs' commercial policy), one can understand the major forces influencing the PFA behavior. In particular, one that emerges clearly is that the undesirable events, or relevant risks faced by a PFA, are of a relative kind (e.g., to underperform 
the industry due to differences in the selected asset allocation), while those that matter to the pension fund participant are the events associated with the not receiving a reasonable pension, in view with the contributions made when young.

In response to this situation many industry observers have raise the need to introduce a risk measure aimed at limiting the adoption of investment strategies that may be undesirable from the point of view of the pension system's participants, in terms of excessive risk taking. One of the alternatives that have been proposed is to adopt a risk measure from a related industry, the most popular one being the Value-at-Risk (VaR) measure [Jorion (2001)], recently adopted by the Mexican pension regulator, which is simply the quantile of the loss distribution associated to a given confidence level. Despite its popularity, there are at least two reasons that make a risk measure based on short-term fluctuations inappropriate for a long-term investor like a pension fund. The first one is related to the unit of account that is usually employed (a nummeraire problem), while the second is related to the need of characterizing the investment decisions of the fund manager. In what follows we elaborate briefly on each one.

The Chilean pension system considers two alternatives in the asset deccumulation phase: annuitization and programmed withdrawals, as well as the combination of both. The first one consists in the purchase of an annuity from an insurance company, while the second one implies the withdrawal of an amount equivalent to the annuity that could be financed with the funds in the individual account (amount which is recomputed annually), so that the participant maintains the property of the funds in the individual account. This last feature may serve the purpose of allowing the participant to choose a better timing for full annuitization, or perhaps, to fulfill a bequest motive; Horneff et al. (2006), Milevsky and Young (2007). As a consequence, the annuity price at the time of retirement is a key determinant of the consumption stream that the participant will be able to finance during the retirement phase. It then follows that if the actions of the regulator are aimed at limiting the short-term negative fluctuations of the pension funds, it well may be the case that these actions end up restricting the adoption of investment strategies that in terms of the final pension would be in principle beneficial from the perspective of the participant. This would be the case, for instance, if the pension fund had a long position in long term bonds whose prices can get negatively affected by an upward shift in the (term structure of) interest rates, although from the point of view of the future pension 
such a fluctuation would be immaterial; see, e.g., Walker (2005) and Cairns et al. (2006).

The second consideration comes from the relatively short horizon considered by most risk measures. In this sense, what is relevant for the pension regulator is to influence the distribution of final pensions. The efforts to influence the short-term distribution of the pension fund (even when the correct nummeraire is being used) are at best a suboptimal situation. The key input between these two distributions is the investment policy selected by the pension fund manager, defined as a contingent asset allocation plan (i.e., a function of time and the states of the world).

This paper proposes a methodology to assess the riskiness of the investment strategy of a portfolio manager in a defined contribution pension system by focusing its attention on the distribution of final pensions, and that has the potential to incorporate the two considerations discussed above, that is, to consider simultaneously an appropriate nummeraire and the distribution of final pensions in the assessment of the risk that is borne by a pension fund participant. To this end, and given the nature of the incentives that are faced by the PFA, we consider an intertemporal portfolio choice problem which is similar in spirit to the one postulated by Roll (1992), who considered a tracking-error problem with respect to a benchmark portfolio. In order to consider dynamic investment strategies, we make use of the dynamic version of such a problem, recently studied by Bajeux-Besnainou et al. (2005), to later on employ the optimal (dynamic) investment strategy of the portfolio manager as an input in the assessment of the riskiness of the investment strategy selected by the PFA, which is done in terms of the distribution of final pensions and the preferences of the representative pension fund participant.

By considering a simplified economic environment, we are able to numerically estimate the Wealth-at-Risk (WaR) of a representative participant, defined as the monetary compensation that leaves the participant indifferent in relation to his/her outside option, whatever this may be. We found that participants which are less risk averse are those exposed to the higher risks, a result that comes from the fact that the outside option under consideration (the utility maximizing benchmark) is higher the less risk averse the participant is.

We also found evidence suggesting that the common belief that a world with more volatile stocks is riskier, when thinking in terms of Wealth-at-Risk, may be misleading. In fact, we found that the WaR (or necessary compensation) increases when stock return 
volatility decreases, a result that follows from the fact that, when volatility decreases, the outside option under consideration increases relatively more that the benefit that the individual derives from the pension provided by the pension fund manager.

The paper is organized as follows. Section 2 briefly reviews the literature on risk measures in dynamic settings to then introduce a dynamic risk measure based on the preferences of the representative participant, which will be at the center of our attention. Section 3 describes the economic environment and characterizes the optimization problems faced by the representative participant and the pension fund manager. Section 4 develops a numerical exercise to illustrate the main findings, and section 5 briefly concludes.

\section{Monetary risk measures}

The term risk was introduced into the economic literature in the paper by Rothschild and Stiglitz (1970), through the concept of second order stochastic dominance (SSD), a concept intended to establish a preference order among uncertain outcomes. ${ }^{1}$ Even though the criterion was fairly intuitive, its generality turned out to be its main weakness when confronted to the task of being used as a decision tool. In particular, the preference order induced by SSD is a partial ordering, so it is not possible to establish an order of preferences between any pair of uncertain outcomes. Almost 30 years later, the need to have a well structured theory found its answer in the work of Artzner et al. (1999), which gave birth to an axiomatic development of coherent risk measures. Formally, these authors defined a risk measure as a mapping of the form $\rho(\cdot): \mathcal{X} \mapsto \varrho \subseteq[-\infty,+\infty]$, where $\mathcal{X}$ stands for the set of random variables representing the possible outcomes of future networth, that satisfy the following set of axioms:

- (monotonicity) $X \geq Y \Rightarrow \rho(X) \leq \rho(Y), \forall X, Y \in \mathcal{X}$.

- (subadditivity) $\rho(X+Y) \leq \rho(X)+\rho(Y), \forall X, Y \in \mathcal{X}$.

- (translation invariance) $\rho(X+a)=\rho(X)-a, \forall X \in \mathcal{X}, \forall a \in \mathbb{R}$.

\footnotetext{
${ }^{1}$ The SSD concept states that among two uncertain consumption bundles, with the same expected value, say $X, Y: \Omega \mapsto \mathcal{R} \subseteq \mathbb{R}_{+}$, where $\Omega$ is the set of states of nature, $X$ is strictly preferred to (or less risky than) $Y$, if and only if, $\mathbb{E}_{\mathbb{P}}[u(X)]>\mathbb{E}_{\mathbb{P}}[u(Y)]$, where $u(\cdot): \mathbb{R}_{+} \mapsto \mathbb{R}$ is an increasing and concave utility function, and $\mathbb{E}_{\mathbb{P}}[\cdot]$ is the mathematical expectation computed under some probability measure $\mathbb{P}$.
} 
- (positive homogeneity) $\rho(\lambda X)=\lambda \rho(X), \forall \lambda \geq 0, \forall X \in \mathcal{X}$.

The interpretation of these axioms is straightforward and intuitive. The first one says that the holding of a financial position $(X)$ which renders a future net worth greater than another $(Y)$, in every state of the world, should be less risky. The second one incorporates the well-known notion of diversification. The third one establishes that the riskless component of a financial position decreases its risk on a one-by-one basis, while the fourth axiom emphasizes the linear growth of the risk measurement.

Among these four axioms initially postulated, the fourth one has been criticized on the grounds of the illiquidity problems that the holding of a sizeable financial position could entail. Additionally, from the point of view of the regulator, the systemic risk in an industry could increase more than linearly as the number of players in the industry gets reduced, so that the linear growth in a risk measure might not be a desirable attribute. The potential problems motivated by these considerations gave rise to more conservative axioms, resulting in what is now known as convex risk measures [Frittelli and Rosazza Gianin (2002), Föllmer and Schied (2002)] which are those that satisfy the properties of monotonicity, translation invariance, and the following one in replace of the subadditivity axiom,

- (convexity) $\rho(\lambda X+(1-\lambda) Y) \leq \lambda \rho(X)+(1-\lambda) \rho(Y), \forall X, Y \in \mathcal{X}, \lambda \in[0,1]$.

One of the most distinctive elements of the theoretical construct proposed by Artzner et al., was the use of a set of acceptable future networths, ${ }^{2}$ from where the risk measurement of a financial position is defined as the smallest distance to the set of acceptable future networths. In this sense, Scandolo (2004) postulates the study of this problem by means of a capital requirement, a concept defined by:

$$
\rho_{\mathcal{A}} \triangleq \inf \{Z \in \mathbb{R}: Z+X \in \mathcal{A} \subseteq \mathcal{X}\},
$$

where $\mathcal{A}$ represents the set of acceptable future networths. The capital requirement $\rho_{\mathcal{A}}$ is therefore given by the smallest amount required to be added (in the present) to make the holding of the financial position $X$, whose value will be realized in the future, acceptable in the present time.

\footnotetext{
${ }^{2}$ In their original work, the set of acceptable future networths is to be defined by the regulator, or the counterparty in a financial transaction that bears the consequences of a financial decision made a third party.
} 
Among others, Scandolo also shows that the acceptable set described by the set

$$
\mathcal{A}^{\mathrm{VaR}} \triangleq\{X \in \mathcal{X}: \mathbb{P}(X<0) \leq \alpha \in[0,1]\}
$$

associated to the Value-at-Risk measure, fails to be convex in general, which implies the non-convexity of its associated capital requirement,

$$
\rho_{\mathcal{A}}^{\mathrm{VaR}} \triangleq \inf \{Z \in \mathbb{R}: \mathbb{P}(Z+X<0) \leq \alpha\}
$$

Other acceptable sets that do satisfy the properties of monotonicity and convexity are those associated to risk measures based on the worse conditional measure,

$$
\mathcal{A}^{\mathrm{WCM}} \triangleq\left\{X \in \mathcal{X}: \mathbb{E}_{\mathbb{P}}(X \mid A) \geq 0, \forall A \in \mathcal{F} \text { with } \mathbb{P}(A) \geq 0\right\},
$$

those related to stress tests,

$$
\mathcal{A}^{\text {STRESS }} \triangleq\left\{X \in \mathcal{X}: \mathbb{E}_{\mathbb{P}_{m}} X \geq 0 \forall m, \mathbb{E}_{\mathbb{Q}_{n}} X \geq F\left(\mathbb{Q}_{n}\right) \forall n\right\},
$$

where $\mathbb{P}_{m}$ and $\mathbb{Q}_{n}$ are probability measures that amplify the frequency of specially adverse events; and those based on increasing and concave expected utility functions,

$$
\mathcal{A}^{u} \triangleq\left\{X \in \mathcal{X}: \mathbb{E}_{\mathbb{P}} u(X) \geq \mathbb{E}_{\mathbb{P}} u(\hat{X})\right\},
$$

with $\hat{X}$ given.

In this article we will deal with a risk measure associated with acceptable sets of the type in (1), where $U=\mathbb{E}_{\mathbb{P}} u(X)$ will stand for an expected utility index representing the preferences of the representative pension fund participant.

Due to the dynamic nature of the portfolio manager's problem to be introduced in the next section, we need to deal with the intertemporal assessment of the riskiness implicit in the investment strategy of the portfolio manager. On this subject, Detlefsen and Scandolo (2005) have shown that under suitable conditions it is possible to define a dynamic risk measure as a family $\left(\rho_{t}\right)_{t \in[0, T]}$ of conditional risk measures adapted to a given information filtration, where $[0, T]$ denotes the length of the participant's planning horizon. In such a setting, these authors have postulated additional properties of time-consistency for a dynamic risk measure. These properties are as follows (where $0<t_{1}<\cdots<t_{n}<T$ is a partition of the planning horizon): 
- (intertemporal consistency) $\rho_{t_{i+1}}\left(X_{T}\right)=\rho_{t_{i+1}}\left(Y_{T}\right) \Rightarrow \rho_{t_{i}}\left(X_{T}\right)=\rho_{t_{i}}\left(Y_{T}\right), \forall X_{T}, Y_{T} \in \mathcal{X}$, $1 \leq i \leq n-1$.

- (recursivity) $\rho_{t_{i}}\left(X_{T}\right)=\rho_{t_{i}}\left(-\rho_{t_{i+1}}\left(X_{T}\right)\right), \forall X \in \mathcal{X}, 1 \leq i \leq n-1$.

- (supermartingale) $\rho_{t_{i}}\left(X_{T}\right) \geq \mathbb{E}_{t_{i}}\left[\rho_{t_{i+1}}\left(X_{T}\right)\right], \forall X \in \mathcal{X}, 1 \leq i \leq n-1$.

The first property is based on the following intuition: if two financial positions will have the same riskiness tomorrow (in each state of the world), the same conclusion should be obtained today. The second property follows from the intertemporal consistency of the translation invariance property, while the last one emphasizes the fact that as the information is revealed, the riskiness of the of the financial position should decrease.

In this article we will consider a dynamic entropic risk measure which is the name that receives a capital requirement when $u$ is an exponential utility function.

\section{The behavioral model}

This section develops a model that is aimed at capturing the main motivations behind the PFAs' decisions, to then study the consequences that such behavior has on the resulting distribution of pensions and the participant's well-being. The model starts by recognizing the strong herding behavior that surrounds the portfolio decisions of most PFAs in private pension systems with individual accounts (Srinivas et al. [2000]). This element is considered by introducing an exogenous benchmark portfolio which enters as a relevant consideration in the portfolio choice problem of the PFA. The solution to this problem is then used to determine the terminal value of the individual account of the participant.

In order to conduct the analysis, we consider a representative participant. ${ }^{3}$ In particular, we assume that the welfare of the representative participant is related to the pension he/she is able to finance with the terminal balance of his/her retirement account at the time of retirement, time that we suppose to be exogenous for all purposes. The last step of our analysis is to quantify the risk (measured as a capital requirement) to which the participant is exposed to. To this end we employ a dynamic convex risk measure based on the participant's preferences.

\footnotetext{
${ }^{3} \mathrm{~A}$ welfare analysis about the consequences that a limited number of investment vehicles has in the presence of heterogeneous investors is conducted by De Palma and Prigent (2004).
} 
The next sub-sections describe the economic environment under consideration, and formally present the decision problems of the PFA and the representative participant.

\subsection{Economic environment}

(UNCERTAINTY) Time is continuous on an infinite horizon. The uncertainty is generated by a $d$-dimensional Brownian motion process, $W \in \mathbb{R}^{d}$, defined on a complete, filtered probability space, $\left(\Omega, \mathcal{F}, \mathbb{F}=\left\{\mathcal{F}_{t}\right\}_{t \geq 0}, \mathbb{P}\right)$, where $\mathbb{P}$ is the natural probability measure defined on $(\Omega, \mathcal{F})$. Given that our interest is placed on the characterization of the situation of interest, in what follows we will only point out the most relevant technical conditions, and will assume that all processes to be introduced are well-defined. In particular, all processes to appear have a strong solution, and all expressions involving (in)equalities of random variables are to be understood to hold in the almost sure sense; that is, for any two given random variables, $x(\omega), y(\omega): \Omega \mapsto \mathbb{R}$, the expression $x(\omega) \geq y(\omega)$ is to be understood in the sense that $\mathbb{P}(x(\omega) \geq y(\omega))=1$.

(CONSUMPTION SPACE) We consider an economy with a single perishable consumption good that will be taken as the nummeraire. The consumption space is given by consumption bundles $X \in \mathcal{X} \triangleq L_{+}^{2}(\Omega, \mathcal{F}, \mathbb{P})$, where $L_{+}^{2}$ is the space of square integrable random variables. ${ }^{4}$

(PREFERENCES) The economy under consideration is populated by two agents, a representative participant of a pension fund, and a PFA. The preferences of the participant are represented by a standard von Neumann-Morgenstern index, defined over the value of the individual account at retirement, $X_{T} \in \mathcal{X}, T>0$, of the form: $U_{t}\left(X_{T}\right) \triangleq \mathbb{E}_{t}\left[u\left(X_{T}\right)\right]$, where $\mathbb{E}_{t}[\cdot] \triangleq \mathbb{E}\left[\cdot \mid \mathcal{F}_{t}\right], \forall t \in[0, T]$, is the mathematical expectation, conditional on the information set at time $t\left(\mathcal{F}_{t}\right)$, and the mapping $u(\cdot): \mathbb{R}_{+} \mapsto \mathbb{R}$ is of class $C^{2}(\mathbb{R})$, with $u^{\prime}(\cdot)>0, u^{\prime \prime}(\cdot)<0$, which in addition satisfies Inada endpoint condition at infinity with $u^{\prime}(+0) \triangleq \lim _{X \downarrow 0} u^{\prime}(X) \leq \infty$. In the case of the PFA's preferences, they are characterized by a tracking error problem to be introduced below (Section 3.3).

(FINANCIAL MARKET) We consider a frictionless financial market where all sources of uncertainty (generated by $W$ ) can be hedged away; that is, we consider a (dynamically)

\footnotetext{
${ }^{4} \mathrm{~A}$ random variable $x$ is called $p$-integrable if $\mathbb{P}\left(x^{p}<\infty\right)=1$. When $p=1, x$ is called integrable. When $p=2, x$ is called squared integrable.
} 
complete financial market with no transaction costs, where the agents can rebalance there portfolios continuously; Merton $(1969,1971)$. In particular the financial market is comprised of $d+1$ assets, represented by a (locally) riskless money-market account ( $B \equiv$ $\left.\left(B_{t}\right)_{t \geq 0}\right)$, and $d$ (locally) risky securities $\left(S \equiv\left\{\left(S_{t}^{i}\right)_{t \geq 0}\right\}_{1 \leq i \leq d}\right)$. The dynamics of these assets is dictated by the following system:

$$
\left\{\begin{array}{l}
d B_{t}=r_{t} B_{t} d t, \quad B_{0}=1, \\
d S_{t}+\delta_{t} d t=\mathbf{I}_{S}\left(\mu_{t} d t+\sigma_{t} d W_{t}\right), \quad S_{0} \in \mathbb{R}_{++}^{d} \text { given, }
\end{array}\right.
$$

where $\mathbf{I}_{S}$ is a diagonal matrix of dimension $d$, that contains the price of each risky asset on its diagonal, and the quantities

$$
(r, \mu, \delta, \sigma) \equiv\left\{\left(r_{t}, \mu_{t}, \delta_{t}, \sigma_{t}\right) \in \mathbb{R}_{+} \times \mathbb{R}_{+}^{d} \times \mathbb{R}_{+}^{d} \times \mathbb{R}^{d \times d} /\{0\}\right\}_{t \geq 0}
$$

are functions of the trajectories of $W$ (or Itô processes) that satisfy the conditions for $B$ and $S$ to be integrable processes. ${ }^{5}$ They represent, respectively, the instantaneous interest rate, the expected return of the risky securities, their corresponding expected dividend, and the volatility matrix.

(PENSION FUND) The evolution of the pension fund, described by $F^{\pi} \equiv\left\{F_{t}^{\pi} \geq 0\right\}_{0<t \leq T}$, is determined by the dynamic investment strategy adopted by the PFA, $\pi \equiv\left\{\pi_{t} \in\right.$ $\left.\mathbb{R}^{d}\right\}_{0 \leq t \leq T}$, where $\pi_{t}$ stands for the dollar amount invested in each of the risky assets. For a given investment strategy, the dynamics of the pension fund is governed by the following system:

$$
\left\{\begin{array}{l}
d F_{t}^{\pi}=\left[F_{t}^{\pi}-\pi_{t}^{\prime} \mathbf{1}\right] r_{t} d t+\pi_{t}^{\prime}\left[\mathbf{I}_{S}^{-1}\left(d S_{t}+\delta_{t} d t\right)\right]+d e_{t} ; \\
F_{0}>0 ; F_{t}^{\pi}+\mathbb{E}_{t}\left[\int_{t}^{T} \xi_{t, s} d e_{s}\right] \geq 0, \forall t \in[0, T] ; \quad F_{T}=F_{T}^{\pi},
\end{array}\right.
$$

where $d e_{t} \geq 0$ is the contribution made by the participant,

$$
\xi_{t, s} \triangleq \exp \left(-\int_{t}^{s}\left(r_{u}+\frac{1}{2} \theta_{u}^{\prime} \theta_{u}\right) d u-\int_{t}^{s} \theta_{u}^{\prime} d W_{u}\right),
$$

where $\theta \triangleq \sigma^{-1}(\mu-r \mathbf{1})$ is known as the market price of risk (MPR), is the stochastic discount factor (SDF) that is consistent with the absence of arbitrage opportunities. ${ }^{6}$ The

\footnotetext{
${ }^{5}$ A stochastic process $x$ is called $p$-integrable if $\mathbb{P}\left(\int_{0}^{T} x_{t}^{p} d t<\infty\right)=1$. When $p=1, x$ is called integrable. When $p=2, x$ is called squared integrable.

${ }^{6}$ The SDF is the time-t price of acquiring one unit of the nummeraire good which is to be delivered (with certainty) at a later time $s$.
} 
symbol (') denotes transposition, $\mathbf{1}=(1, \ldots, 1)^{\prime} \in \mathbb{R}^{d}, F_{t}^{\pi}-\pi_{t}^{\prime} \mathbf{1}$ represents the amount invested in the money-market account (that provides a return of $r_{t}$ between $t$ and $t+d t$ ), while the remainder, $\pi_{t}^{\prime} \mathbf{1}$, denotes the amount invested in the risky assets (that provides a return given by capital gains plus dividends $\left(d S_{t}^{i}+\delta_{t}^{i} d t\right) / S_{t}^{i}$, between $t$ and $t+d t$, for $i=1, \ldots, d)$.

(INVESTMENT PLANS) In what follows, we will denote the set of investment plans that satisfy the system in (3), along with the conditions $\operatorname{VAR}\left(F_{T}\right)<\infty$ and $F_{t}^{\pi}$ being a squared integrable process, by $\mathcal{A}^{\pi}\left(F_{0}\right)$. A dynamic investment plan $\pi \in \mathcal{A}^{\pi}\left(F_{0}\right)$ will be called admissible.

\subsection{The problem of the representative participant}

We now analyze the problem of the representative participant, whose well-being at time $t$ is represented by the index $U_{t}\left(X_{T}\right)$. In order to explicitly consider the nummeraire problem that we mentioned in section 1 , we will assume that $U_{t}$ takes the following form:

$$
U_{t}\left(\hat{X}_{T}\right) \triangleq \mathbb{E}_{t}\left[1-\exp \left\{-\gamma \frac{\hat{X}_{T}}{a_{T}}\right\}\right], \forall t \in[0, T],
$$

where $\gamma>0$ is the Arrow-Pratt absolute risk aversion coefficient,

$$
\gamma=-u^{\prime \prime}(\hat{X}) / u^{\prime}(\hat{X})
$$

and $a_{T}$ denotes the price of a one dollar paying immediate constant annuity that start paying at time $T .^{7}$

The expression in (4) assumes that the participant annuitizes the full value of the retirement account at retirement. Even though most mandatory private pension systems based on individual account consider an additional disbursement alternative, called programmed withdrawals, the amount of the disbursements of this latter alternative is closely related to the value of $a_{T}$. In this sense, the assumption is not particularly restrictive.

\footnotetext{
${ }^{7} \mathrm{~A}$ constant life annuity is a contract between a buyer (annuitant) and a seller (insurer) that pays out a constant periodic amount for as long as the buyer is alive, in exchange for an initial premium; Brown et al. (2001). The insurer collects the premiums and invests them in order to meet liabilities arising from the payouts.
} 
Remark 1 The adoption of the functional form in (4) is directly related to the convenience form of the capital requirement that results when the set of acceptable future networths 8

$$
\mathcal{A}_{t}^{u} \triangleq\left\{X_{T}^{\pi} \in \mathcal{X}: U_{t}\left(X_{T}^{\pi}\right) \geq U_{t}\left(\hat{X}_{T}\right)\right\},
$$

where $X_{T}^{\pi}$ is the terminal value of the retirement account generated by the investment strategy $\pi$, chosen by the PFA, while $\hat{X}_{T}$ corresponds to a subjective reference value set by the participant, that might account for his/her outside option given by, for instance, investing on his/her own.

In the case of a participant with a high expertise in financial affairs, it would be natural to set $\hat{X}_{T}$ as the quantity that is the solution to the problem, ${ }^{9}$

$$
\max _{\pi \in \mathcal{A}^{\pi}\left(F_{0}\right)} U_{0}\left(\hat{X}_{T}^{\pi}\right)
$$

The following remark identifies the optimal value of $\hat{X}_{T}^{\pi}$ that a participant with a high degree of expertise would pursue before retirement.

Remark 2 (the expert's solution) At any time $t \in[0, T]$, the utility of a participant with a high expertise in financial affairs will be given by $U_{t}\left(\hat{X}_{T}^{*}\right)$, where $\hat{X}_{T}^{*} \equiv J\left(y_{t} \xi_{t, T} a_{T}\right)^{+} \triangleq$ $\left(a_{T} / \gamma\right) \ln \left(y_{t} \xi_{t, T} a_{T} / \gamma\right)^{-}, x^{ \pm} \triangleq \max ( \pm x, 0), y_{t}>0$ is the Lagrange multiplier associated to the 'static version' of the budget constraint, that is the solution to ${ }^{10}$

$$
\mathbb{E}_{t}\left[\xi_{t, T} J\left(y_{t} \xi_{t, T} a_{T}\right)^{+}\right]=X_{t}+\mathbb{E}_{t}\left[\int_{t}^{T} \xi_{t, s} d e_{s}\right] .
$$

Proof. The static version of the problem faced by the representative participant at time $t \in$ $[0, T]$ is given by [see, e.g., Karatzas and Shreve (1998, Chapter 4)]:

$$
\max _{X_{T} \in \mathcal{X}} \mathbb{E}_{t}\left[1-\exp \left\{-\gamma \frac{X_{T}}{a_{T}}\right\}\right], \text { subject to: } \mathbb{E}_{t}\left[\xi_{t, T} X_{T}\right] \leq X_{t}+\mathbb{E}_{t}\left[\int_{t}^{T} \xi_{t, s} d e_{s}\right] .
$$

By the concavity of the problem and the non-negativity constraint for $X_{T}$, from the first-orderconditions we obtain $X_{T}^{*}=\left(a_{T} / \gamma\right) \ln \left(y_{t} \xi_{T} a_{T} / \gamma\right)^{-}$. The Lagrange multiplier, $y_{t}$, is obtained by substituting $X_{T}^{*}$ into the static budget constraint, which must hold with equality since $u(\cdot)$ is an strictly increasing function.

\footnotetext{
${ }^{8}$ One of attributes of the capital requirement that results from this acceptable set is given by the fact that the preferences defined by the order $X \succsim Y \Leftrightarrow U(X) \geq U(Y)$, are preserved. That is to say, the preferred consumption bundle is also the less risky; see Detlefsen and Scandolo (2005, Remark 11).

${ }^{9}$ Note that given the form of the objective function the solution to (6) is dynamically consistent.

${ }^{10}$ Note that the equation admits a unique solution, and that the following condition must be satisfied $y_{t}>0$.
} 


\subsection{The PFA problem}

In line with the current practice in the Chilean PFA industry, we assume that PFA's investment decisions can be characterized by a tracking error problem as in Roll (1992). That is, we assume that the PFA's goal is to minimize the relative volatility between the pension fund and an exogenous benchmark portfolio, $Y$, subject to a minimum expected return performance. Under this assumption, the PFA problem is analogous to the following control problem, for $0 \leq t<s \leq T$,

$$
\min _{F_{s}^{\pi} \geq 0} \operatorname{VAR}\left[F_{s}^{\pi}-Y_{s} \mid \mathcal{F}_{t}\right], \quad \text { subject to: } \mathbb{E}_{t}\left[F_{s}^{\pi}\right]=F_{t} e^{\bar{r}(s-t)}, \quad F_{t}>0,
$$

where $\bar{r}>0$ is the minimum return performance set by the PFA, and $Y_{s} \geq 0$ is the terminal position of the benchmark portfolio, whose dynamics is dictated by

$$
d Y_{u}=Y_{u} \mu_{u}^{Y} d u+Y_{u}\left(\sigma_{u}^{Y}\right)^{\prime} d W_{u}+d e_{u}, \quad Y_{t}=F_{t}
$$

where $\mu_{u}^{Y}=\left[\left(1-\phi_{u}^{\prime} \mathbf{1}\right) r_{u}+\phi_{u}^{\prime} \mu_{u}\right]$ and $\sigma_{u}^{Y}=\phi_{u}^{\prime} \sigma_{u}$ denote, respectively, the expected return of the benchmark portfolio (resulting from the amounts invested in the money-market account and the whole set of risky assets) and its volatility, while $\phi_{u} \in[0,1]^{d}$ stands for the fraction invested by the benchmark portfolio in each one of the (locally) risky assets.

It is important to note that the investment horizon of the PFA $(s-t)$ may differ from the planning horizon of the representative participant $(T-t)$. This is so due to the fact that the compensation scheme of the pension fund manager may be tilted towards a shorter horizon. ${ }^{11}$

Problem (P1) has been recently studied by Bajeux Besnainou et al. (2005), who have extended the results of Bajeux Besnainou and Portait (1998) to the case of dynamic meanvariance problems in presence of benchmark portfolios. One of the most interesting results of the research program undertaken by these authors is the characterization of the solution of dynamic portfolio choice problems, by means of static (i.e., buy-and-hold) investment strategies whose underlying components are portfolios that are rebalanced dynamically. The identification of these portfolios allows the complete characterization of the optimal investment plan of the fund manager. The next proposition characterize the solution of problem (P1).

\footnotetext{
${ }^{11}$ Mangiero et al. (2006) found that compensation schemes of Chilean pension fund managers are designed towards relatively short horizons (less than 2 years).
} 
Proposition 1 (Bajeux Besnainou et al. (2005)) The solution of problem (P1)) is given by

$$
F_{s}^{* *}=Y_{s}+\kappa_{t, s}-\left[\kappa_{t, s} B_{s}(t)\right] L_{t, s}
$$

where $\kappa_{t, s} \equiv\left(1-\left\{B_{s}(t)^{2} / \mathbb{E}_{t}\left[\tilde{\xi}_{t, s}^{2}\right]\right\}\right) /\left(2\left(F_{t} e^{\bar{r}(s-t)}-\mathbb{E}_{t}\left[Y_{s}\right]\right)\right), B_{s}(t)$ is the time-t price of a zero coupon bond of maturity $s$, and $L_{t, s} \equiv \xi_{t, s} / \mathbb{E}_{t}\left[\xi_{t, s}^{2}\right]$ denotes the payoff associated to the minimum norm portfolio. ${ }^{12}$ The investment strategy associated with $F_{s}^{* *}$ is of the buy-and-hold type. It is comprised of: (1) a long position in the portfolio that replicates the benchmark portfolio by an amount of $F_{t}$, (2) a long (resp. short) position in the zero coupon bond by an amount of $\kappa_{t, s} B_{s}(t)$ if $\kappa_{t, s} B_{s}(t)>(<) 0$, and (3) a short (long) position in the minimum norm portfolio if $\kappa_{t, s} B_{s}(t)>(<) 0$ by an mount of $\kappa_{t, s} B_{s}(t)$.

Proof. See Bajeux Besnainou et al. (2005, Proposition 1).

Remark 3 The investment strategy of the pension fund manager will be (dynamically) meanvariance efficient as long as the benchmark portfolio (Y) is efficient as well; Roll (1992). BajeuxBesnainou and Portait characterize the set of (dynamically) mean-variance efficient portfolios as those that can be written in the form $F_{s}=a-b L_{s}$, with $a, b \in \mathbb{R}_{++}$.

From the expression in (7) we can see the need to impose further structure on the functional forms of the quantities $(r, \theta)$, in order for the investment strategy in Proposition 1 to be actually identified. This is so due to the fact that the quantities $\kappa_{t, s}, B_{s}(t)$ and $L_{t, s}$ implicitly depend upon the expressions $\mathbb{E}_{t}\left[\xi_{t, s}\right], \mathbb{E}_{t}\left[Y_{s}\right]$ and $\mathbb{E}_{t}\left[\tilde{\xi}_{t, s}^{2}\right], 0 \leq t<s \leq T$. With this in view, the numerical exercise developed in the next section imposes simplifying assumptions on the dynamics of these quantities.

\section{Numerical exercise}

This section illustrates by means of a numerical exercise the relationship between the investment strategy of the benchmark portfolio, and the fraction of the present value of the participant's wealth,

$$
A_{t} \triangleq X_{t}+\mathbb{E}_{t}\left[\int_{t}^{T} \xi_{t, s} d e_{s}\right]
$$

\footnotetext{
${ }^{12}$ Bajeux Besnainou and Portait $(1998, \S 2.2)$ show that the return of the minimum norm portfolio is the one that minimizes the second moment among all admissible portfolios.
} 
that is accounted for the capital requirement

$$
\rho_{t}^{u}\left(X_{T}^{* *}\right)=\inf \left\{Z_{t} \in L^{2}\left(\mathcal{F}_{t}\right): U_{t}\left(X_{T}^{* *}+Z_{t}\right) \geq U_{t}\left(\hat{X}_{T}^{*}\right)\right\}
$$

This last quantity is to be denominated in the risk-free security, which in our case corresponds to a one dollar paying annuity, deferred by $T-t$ years. We will called this quantity the Wealth-at-Risk (WaR) of a participant associated with the outside option $\hat{X}$.

For the case of exponential preferences, the capital requirement $\left(\rho_{t}^{u}\left(X_{T}^{* *}\right)\right)$ is given by the expression

$$
\rho_{t}^{u}\left(X_{T}^{* *}\right)=\frac{1}{\gamma} \ln \left(\mathbb{E}_{t}\left[\exp \left\{-\gamma \frac{X_{T}^{* *}}{a_{T}}\right\}\right]\right)-\frac{1}{\gamma} \ln \left(\mathbb{E}_{t}\left[\exp \left\{-\gamma \frac{\hat{X}_{T}^{*}}{a_{T}}\right\}\right]\right) .
$$

In addition, the rational price of a one-dollar paying annuity, deferred by $T-t$ years, corresponds to

$$
{ }_{T-t} a_{T}=\mathbb{E}_{t}\left[\int_{T}^{\infty} \xi_{t, s}\left(s p_{t}\right) d s\right],
$$

where $\left({ }_{s} p_{t}\right)$ stands for the probability that a participant of age $t$ survives for $s-t$ additional years. ${ }^{13}$ The WaR at time $t$ is therefore given by $\rho_{t}^{u}\left(X_{T}^{* *}\right) /\left(A_{t} /{ }_{T-t} a_{T}\right)$.

\subsection{A parametric model}

We study the simplest model possible in order to carry out the analysis. In particular, we consider a model with a single source of uncertainty $(d=1)$ and two financial assets. The dynamics of these assets is given by the system

$$
\begin{aligned}
& d B_{t} / B_{t}=r_{t} d t, \quad B_{0}=1, \\
& d S_{t} / S_{t}=\left(\mu+r_{t}\right) d t+\sigma d W_{t}, \quad S_{0} \in \mathbb{R}_{++} \text {given, }
\end{aligned}
$$

$(\mu, \sigma) \in \mathbb{R}_{++}^{2}$, where for the instantaneous interest rate we adopt a Vasicek (1977) specification, ${ }^{14}$

$$
d r_{t}=\lambda_{r}\left(\kappa_{r}-r_{t}\right) d t-\sigma_{r} d W_{t}, \quad r_{0} \text { given. }
$$

\footnotetext{
${ }^{13}$ We referred the interested reader to Milevsky (2006) for a comprehensive introduction of actuarial science and its concepts.

${ }^{14}$ We notice that the interest rate dynamics is written with a negative sign on the volatility parameter, which is assumed positive. As will become clear later, this assures that all volatilities in the model are positive and induces the negative correlation between interest rates and stock and bond prices that is typically observed.
} 
Our interest in modelling the dynamics of the interest rate (IR) is based on our worry to not overstate the riskiness of equity. In particular, we want to consider the negative correlation between IR and stocks prices and deferred annuities (or long term bond) prices.

Another factor that we take into account is the difference between the investment horizon of the PFA and the planning horizon of the pension fund participant. In particular, the exercise considers an investment horizon of one month in the PFA problem, while the planning horizon of the participant is one of the variables to be examined.

Additionally, we assume that biometric and financial sources of uncertainty are independent. In particular, in the computation of the deferred annuity price [equation (9)] we employed a mortality distribution governed by a law of the Gompertz-Makeham type [Carriere (1994)], with a force of mortality given by $\lambda_{t}=\lambda+(1 / b) \exp \{(t-m) / b\}$, where $\lambda>0$ is a constant that captures accidental mortality factors, while $(m, b)$ are parameters of the distributions that need to be estimated. Under these assumptions, the probability of survival of an individual of age $t$, for $s-t$ additional years, is given by [see, e.g., Charupat and Milevsky (2002)]

$$
\begin{aligned}
{ }_{s} p_{t} & =\exp \left\{-\lambda(s-t)-\frac{1}{b} \int_{t}^{s} e^{((s-t)-m) / b} d s\right\} \\
& =\exp \left\{-\lambda(s-t)+b\left(\lambda_{t}-\lambda\right)\left(1-e^{(s-t) / b}\right)\right\} .
\end{aligned}
$$

Consequently, the rational price of a deferred annuity under the Vasicek specification is given by

$$
\left.{ }_{T-t} a_{T}=\int_{T}^{\infty}\left[\exp \left\{m(t, s)-n(t, s) r_{t}-\lambda(s-t)\right)+b\left(\lambda_{t}-\lambda\right)\left(1-e^{(s-t) / b}\right)\right\}\right] d s
$$

where [see, for instance, Glasserman (2004)]

$$
\begin{aligned}
m(t, s)= & -\left(\kappa_{r}+\sigma_{r} \theta / \lambda_{r}\right)\left[(s-t)+\frac{1}{\lambda_{r}}\left[e^{-\lambda_{r}(s-t)}-1\right]\right]+ \\
& \frac{\sigma_{r}^{2}}{2 \lambda_{r}^{2}}\left[(s-t)+\frac{1}{2 \lambda_{r}}\left(1-e^{-2 \lambda_{r}(s-t)}\right)+\frac{2}{\lambda_{r}}\left(e^{-\lambda_{r}(s-t)}-1\right)\right], \\
n(t, s)= & \frac{1}{\lambda_{r}}\left(1-e^{-\lambda_{r}(s-t)}\right) .
\end{aligned}
$$

In spite of the simplicity of the model under consideration, the expression in (8) cannot be computed analytically. Fortunately, its structure is amenable for Monte Carlo simulation, which is the avenue we pursue in what follows. 


\subsection{Calibration}

We calibrate all parameters in annual frequency. The interest rate data was obtained from the return of the fixed-income index LVACLI (www.LVAindices.com) for the period 20012006 (1336 observations). The estimated coefficients were $\lambda_{r}=3.6636, \kappa_{r}=0.0394, \sigma_{r}=$ $3.08 \times 10^{-6}$. For the excess return and the volatility of the stock we used the daily returns of the Santiago Stock Exchange Index (IPSA) for the same period $(\mu=0.0889, \sigma=0.2057$ ). In the case of the parameter $\gamma$, we calibrate it in a way that the representative participant were willing to accept the same bets that an individual with CRRA preferences would accept at $t=0$, had the latter a relative risk aversion coefficient in the set $\{1,2,3,4\} .{ }^{15}$

The parameters $(\lambda, m, b)$ were obtained by fitting the survival probabilities of the Gompertz-Makeham function to the official mortality tables at different ages (Superintendency of PFA [2004]) using a non-linear least-square method.

The minimum return performance was set at $\bar{r}=0.05$, and the present value of contributions,

$$
\mathbb{E}_{0}\left[\int_{0}^{T} \xi_{0, t} d e_{t}\right]=\mathbb{E}_{0}\left[\int_{0}^{T} \xi_{0, t} \Delta d t\right],
$$

at 5 , where $\Delta>0$ is the fix contribution made by the participant.

For the baseline case we fixed the investment horizon of the PFA in one month (i.e., $s-t=1 / 12$ ). The final step in the calibration was to restrict the bets of the PFA [second and third terms in (7)] to more realistic values. Using the observed composition of PFAs portfolios we constrained the bets to the such that $\kappa_{t, s} \in \mathcal{K}_{t}=\left[-10 \% Y_{t}, 10 \% Y_{t}\right], \forall t$. All the results to be presented next were computed for a single male that retires at age 65 .

\subsection{Simulation results}

Figure 1 shows the results obtained by a simulation of 10,000 trajectories of a 1-dimensional Wiener process, from which we computed the averages of the quantities involved in the conditional expectations of the expression in (8). ${ }^{16}$ The numbers on the vertical axis in the figure represent the fraction of wealth that a participant should receive at the time

\footnotetext{
${ }^{15}$ An individual with CRRA preferences and a relative risk aversion coefficient in the set $\{1,2,3,4\}$, would be willing to give up to $2.0 \%, 4.0 \%, 6.0 \%$ and $7.6 \%$ of his current wealth, respectively, in order to avoid a fair bet involving a variation in his wealth of $\pm 20 \%$.

${ }^{16}$ The asymptotic properties of this unbiased estimator are analized in detail by Detemple et al. (2006). In our case, the only relevant error is the one produced by the approximation of the conditional expectation by the average of the replications; Glasserman (2004).
} 
of the measurement, in order to reach a level of expected utility equivalent with that of his/her outside option, which is given by the utility maximizing solution, $U_{t}\left(\hat{X}_{T}^{*}\right)$. For the benchmark portfolio that enters into the PFA's portfolio problem we selected the default portfolio of the Chilean system, which allows equity investment to be up to $60 \%$, $40 \%$ and $20 \%$ of the pension fund, depending on the age bracket of the participant from a total of three, where the central age bracket is the widest: from 36 to 55 years of age. For simplicity we assume that the investment strategy of the benchmark is to invest up to the allowable maximum in equity, which is what has been happening since 2002, when the number of investment strategies per pension fund was increased from one to five.

\section{[Figure_01 about here]}

The figure shows the WaR of the median trajectory (50th quantile) of the retirement account balance for different levels of risk aversion. In terms of risk aversion, the less risk averse the participant is, the higher his/her risk exposure (measured as a capital requirement). This is due to the outside option of the participant, $U_{t}\left(\hat{X}_{T}^{*}\right)$, since a less risk averse participant demands a higher compensation in every state of the world (recall the expression $\left.\hat{X}_{T}^{*} \equiv\left(a_{T} / \gamma\right) \ln \left(y_{t} \xi_{t, T} a_{T} / \gamma\right)^{-}\right)$. In particular, for a participant with a risk aversion similar to that of an individual with a RRA coefficient of 1 , the compensation goes from $540 \%$ of his/her total wealth when young, to near $130 \%$ when old, while for a participant with a risk aversion similar to that of an individual with a RRA coefficient of 4 , the required compensation goes down from $210 \%$ to near $55 \%$, respectively. One conclusion that can be drawn from this figure is that a suboptimal investment strategy imply huge losses for a participant, with respect to the one generating the payoff $X_{T}^{*}$. Taking the previous case as our base case scenario, we carried out several exercises of interest, focusing our attention in the associated capital requirement variation, which we called 'Incremental WaR'.

$$
\text { [Figure_02 about here] }
$$

Our first exercise is presented in Figure 2. It presents the incremental WaR (i.e., the WaR change with respect to our baseline case) associated with a benchmark portfolios 
consisting in static buy-and-hold strategies that differ the equity holding in the last age bracket; a change that would have an impact on all participants at different ages. The upper panel in the figure corresponds to the case where the equity holding in the last age bracket is raised to $80 \%$ (from the initial value of $20 \%$ ), while the lower panels correspond to cases in which the equity holding has been changed in $+40 \%,+20 \%$ and $-20 \%$, with respect to the baseline case. From the figure it is possible to see that the WaR of the individual decreases as the equity exposure is decreased, reaching its minimum when the equity exposure is equal to zero, where a WaR reduction of near $20 \%$ is attained.

\section{[Figure_03 about here]}

Our second exercise is presented in Figure 3. It follows the same logic of the previous one, but this time the changes are performed over the middle age bracket ( 36 to 55 years old). The upper panel corresponds to the case where the equity holding has been raised to $80 \%$ (from an initial value of $40 \%$ ), while the lower panels correspond to cases in which the equity holding has been changed in $+20 \%,-20 \%$ and $-40 \%$, with respect to the baseline case. From the figure, it is possible to see that an increase in the equity holding would benefit individuals with lower risk aversion (two upper panels), but it would hurt those who are more risk averse. From the third upper panel one can see that a decrease of $20 \%$ in the equity holding would hurt everybody, while the opposite is true for the case when the equity holding is decreased to zero (bottom panel), where a WaR reduction of near $30 \%$ is obtained for younger participants.

\section{[Figure_04 about here]}

Figure 4 shows the case in which the equity holding is changed for the first age bracket. The upper panel represents the case where the equity holding has been raised to $80 \%$ (from an initial value of $60 \%$ ), while for the lower panels the changes correspond to $-20 \%$, $-40 \%$, and $-60 \%$, with respect to the baseline case. It can be seen that a change in the equity holding for the first bracket is of a lower order of magnitude, with respect to the previous cases. In addition, these changes only affect the distribution of pensions of younger participants, since the portfolio policies affecting older participants remain 
unchanged. The upper panel shows that an increase in the equity holding would benefit individuals with low risk aversion the most. The only case in the figure where a change in equity holding results in a decrease of welfare is the case of a reduction of $40 \%$ (third upper panel). Such a change would hurt younger participants with a risk aversion similar to those with a RRA coefficient of 1 .

\section{[Figure_05 about here]}

In Figure 5 we explore the effects of a decrease in total wealth. We consider two cases: one where the participant has a retirement account balance which is $80 \%$ of the base case (at each time of measurement), and a second one where the participant has an income stream which is $80 \%$ of the baseline case. The first case is presented in the upper panel of Figure 5. the picture shows that the effect is an increase in the WaR which is decreasing in the planning horizon. This means that relative to the baseline case, and after a negative shock has hit the balance of the retirement account, the outside option, $U_{t}\left(\hat{X}_{T}^{*}\right)$, is even more preferred than the one delivered by the pension fund manager, $U_{t}\left(X_{T}^{* *}\right)$. Moreover, the WaR variation is almost identical to all participants, irrespective of their risk aversion.

The second case (i.e., a negative shock in the income stream) is illustrated in the bottom panel of Figure 5. The picture shows that the magnitude of this type of shock is increasing in the planning horizon. The effects are of the same order of magnitude than those in the previous case. From these pictures one can conclude that for individuals with exponential preferences, the portfolio manager should follow a more conservative investment policy after a negative shock has occurred. In addition, the effects are similar to all individuals, irrespective of their risk aversion.

\section{[Figure_07 about here]}

Our last exercise is directed to assess the relation between the stock return volatility and pension risk, when the latter is measured as a capital requirement. To this end we recomputed the incremental WaR relative to our baseline case considering a less volatile stock return ( $80 \%$ of initial volatility). Figure 6 shows our results. They strongly suggest that the common association between risk and stock return volatility can be misleading, at 
least when risk is understood as a capital requirement defined over an acceptable set with an outside option equal to $U_{t}\left(\hat{X}_{T}^{*}\right)$. The picture shows that in a world with less volatile stock return individuals should be compensated with higher amounts. This is due to the fact that the new outside option, $U_{t}\left(\hat{X}_{T}^{*}\right)$, is relatively higher than the one delivered by the fund manager, $U_{t}\left(X_{T}^{* *}\right)$. Behind this result there is a critical point related to the outside option of our choice: the possibility of dynamic rebalancing. Unlike the static buy-andhold investment policy followed by the benchmark portfolio, our outside option reacts to changes in the MPR according to the participant's preferences.

\section{Conclusions}

This paper is a first step in the direction of consistently assessing the investment risk embedded into the portfolio of a pension fund and the investment strategy of a pension fund manager. In particular, it proposes a methodology that focus on the distribution of pensions that is generated by an investment policy that is consistent with the strong herding behavior surrounding fund manager's decisions; the object that matters the most in a mandatory pension system.

Our methodology adopts the point of view of the participant by explicitly modeling his/her preferences, and taking into account the fact that pension fund managers might pursue a different investment goal (e.g., tracking down its own relevant benchmark portfolio). In a sense, the task of regulators is similar to the one of solving a principal-agent program, where the main output of the solution is given by the identification of an appropriate benchmark portfolio for the pension fund manager to pursue.

When pension risk is measured as a capital requirement, which is defined over an outside option given by the utility maximizing policy, our results suggest that a policy maker that cares equally about all participants of the system should worry more about those who are less risk averse (in the classical sense), since they are the ones bearing greater risks. The reason for this is that less risk averse participants are the ones having the higher outside options, and thus the ones demanding higher compensations.

The results from the stylized model presented in section 4 also show that the higher risk reductions are attained when the benchmark portfolio contains a good deal of fixed income securities. In terms of negative shocks to the participant's wealth, shocks to the 
balance of the retirement account or the flow of contributions have similar consequences for all participants.

One clear implication of our results is that there is no direct relationship between stock return volatility and pension risk. In particular, pension risk is shown to increase steeply with a reduction in stock returns volatility, a result that is based on the fact that the outside option of our choice increases relatively more than the utility that the participant derives from the pension delivered by the pension fund manager.

One of the main drawbacks of the proposed methodology is given by the lack of a clear cut to guide policy makers. Many of the policy implications that can be derived from it depends crucially on the particular preferences of the participants, or the specific weights that one may assign to each group on some social welfare function. In this sense, it would be desirable for future work to concentrate on an acceptable set that provides further guidance in these terms.

A second consideration is given by the way in which the proposed methodology can be implemented. In particular, one of the key input needed is the investment policy of the pension fund manager, a policy that would probably be modified when PFAs decisions are framed in an environment subject to (pension) risk limits. These and other considerations will be the focus of a future work.

\section{References}

Artzner, P., Delbaen, F., Eber, J.-M., and D. Heath (1999): “Coherent Measures of Risk," Mathematical Finance 9, 203-228.

Artzner, P., Delbaen, F., Eber, J.-M., Heath, D. and H. Ku (2007): “Coherent Multiperiod Risk Adjusted Values and Bellman's Principle," Annals of Operations Research 152, 5-22.

Bajeux-Besnainou, I. and R. Portait (1998): “Dynamic Asset Allocation in MeanVariance Framework," Management Science 44, S79-S95.

Bajeux-Besnainou, I., Portait, R. and G. Tergny (2005): “Dynamic Asset Allocation with Benchmarking and Performance Constraints," Mimeo.

BASAK, S., SHAPIRO, A. and L. TEPLÁ (2006): “Risk Management with Benchmarking," Management Science 52, 542-557. 
Brown, J., Mitchell, O., Poterba, J. and W. WArshawsky (2001): The Role of Annuity Markets in Financial Retirement. MIT Press: Cambridge (MA).

CARriere, J. (1994): "An Investigation of the Gompertz Law of Mortality," Actuarial Research Clearing House 2.

CAirns, A.J.G., BlaKe, D. and K. Dowd (2006): "Stochastic Lifestyling: Optimal Dynamic Asset Allocation for Defined Contribution Pension Plans," Journal of Economic Dynamics \& Control 30, 843-877.

Charupat, N. and M.A. Milevsky (2002): "Optimal Asset Allocation in Life Annuities: A Note," Insurance: Mathematics \& Economics 30, 199-209.

Cheridito, P., Delbaen, F. and M. Kupper (2004): “Dynamic Monetary Risk Measures for Bounded Discrete-Time Processes," Mimeo.

Cox, J. and C.-F. HuAng (1989): "Optimal Consumption and Portfolio Policies when Asset Prices follow a Diffusion Process," Journal of Economic Theory 49, 33-83.

Cox, J. and C.-F. HuAng (1991): "A Variational Problem Arising in Financial Economics," Journal of Mathematical Economics 20, 465-487.

De Palma, A. and J.-L. Prigent (2004): “Optimal Portfolio Positioning," Mimeo.

Detemple, J.B., García, R. and M. Rindisbacher (2006): “Asymptotic Properties of Monte Carlo Estimators of Diffusion Processes," Journal of Econometrics 134, 1-68.

Detlefsen, K. and G. SCAndolo (2005): "Conditional and Dynamic Convex Risk Measures," Finance \& Stochastics 9, 539-561.

Föllmer, H. and I. Penner (2006): "Convex Risk Measures and the Dynamics of their Penalty Function," Statistics \& Decisions (forthcoming).

Föllmer, H. and A. SChied (2002): "Convex Measures of Risk and Trading Constraints," Finance \& Stochastics 6, 429-447.

FritTelli, M. and E. RosazZA GIANin (2002): "Putting Order in Risk Measures," Journal of Banking \& Finance 26, 1473-1486.

FRITTELli, M. and G. SCANDOlO (2006): "Risk Measures and Capital Requirements for Processes," Mathematical Finance 16, 589-612.. 
Glasserman, P. (2004): Monte Carlo Methods in Financial Engineering. Application of Mathematics No. 53. Springer-Verlag: New York.

Gourieroux, C. and J. JAsiak (2001): Financial Econometrics: Problems, Models, and Methods. Princeton Series in Finance. Princeton University Press: New Jersey.

HornefF, W.J., Maurer, R.H. and M.Z. Stamos (2006): “Life-Cycle Asset Allocation with Annuity Markets: Is Longevity Insurance a Good Deal?," Mimeo. Department of Finance, Johann Wolfgang Goethe-University of Frankfurt.

JORION, P. (2001): Value at Risk: The New Benchmark for Managing Financial Risk (2d. Ed.). McGraw Hill: New York.

Karatzas, I., LehoczKy, J. and S. Shreve (1987): “Optimal Consumption and Portfolio Decisions for a 'Small Investor' on a Finite Horizon," SIAM Journal of Control $\mathcal{E}$ Optimization 25, 1557-1586.

Karatzas, I. and S. Shreve (1998): Methods of Mathematical Finance. Application of Mathematics No. 39. Springer-Verlag: New York.

Mangiero, S., Rocha, R., Thompson, G. and E. WAlker (2006): “Moving to a RiskBased Supervision in Chile," FIRST Technical Assessment Report.

Merton, R.C. (1969): "Lifetime Portfolio Selection under Uncertainty: The ContinuousTime Case," Review of Economics \& Statistics 51, 247-257.

Merton, R.C. (1971): "Optimum Consumption and Portfolio Rules in a Continuoustime Model," Journal of Economic Theory 3, 373-413.

Milevsky, M.A. (2006): The Calculus of Retirement Income: Financial Models for Pension Annuities and Life Insurance. Cambridge University Press: New York.

MilevsKy, M.A. and V.R. Young (2007): “Annuitization and Asset Allocation," Journal of Economic Dynamics \& Control (forthcoming).

Roll, R. (1992): “A Mean/Variance Analysis of Tracking Error," Journal of Portfolio Management $\mathbf{1 3}$ (Summer), 13-22.

Rothschild, M. and J.E. Stiglitz (1970): "Increasing Risk: I. A Definition," Journal of Economic Theory 2, 225-243. 
Scandolo, G. (2003): "Risk Measures in a Dynamic Setting," Ph.D. Thesis, Università degli Studi di Milano.

SCANDOlO, G. (2004): "Models of Capital Requirements in Static and Dynamic Settings," Economic Notes 33, 415-435.

Srinivas, P.S., Whitehouse, E. and J. Yermo (2000): “Regulating Private Pension Fund's Structure, Performance and Investments: Cross-country Evidence," Social Protection Working Paper 0113. The World Bank.

SuPERINTENDENCY OF PFA (2004): “Tabla de Mortalidad RV-2004, Hombres y Mujeres, para pensionados de Viudez del D.L. N ${ }^{o} 3.500$, de 1980," Circular N ${ }^{o} 1.134$.

VASICEK, O. (1977): "An Equilibrium Characterization of the Term Structure," Journal of Financial Economics 5, 177-188.

Walker, E. (2005): "Optimal Portfolios in Defined Contribution Pension Systems," Mimeo. School of Business, P. Universidad Católica de Chile. 
Figure 1

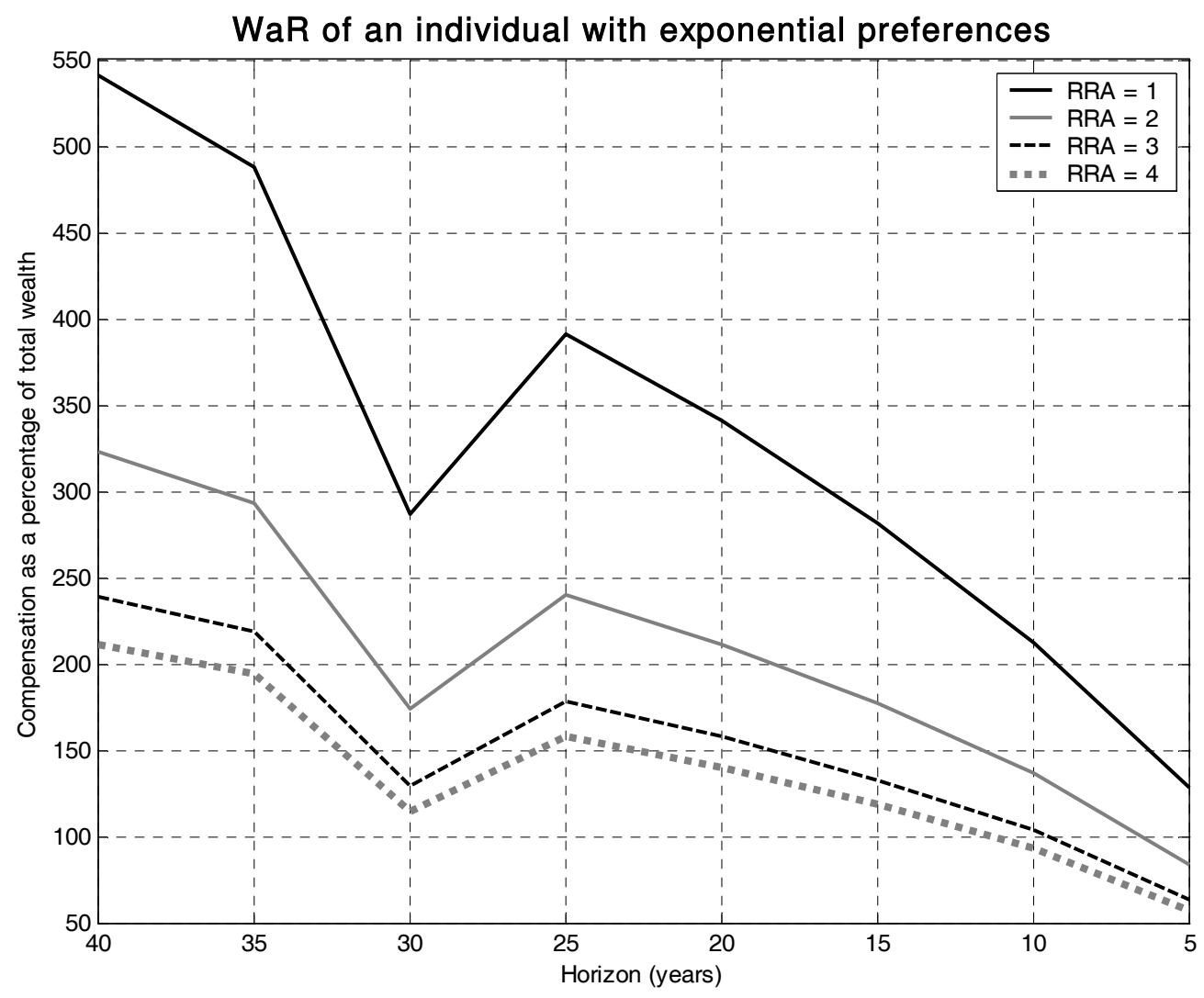


Figure 2

Incremental WaR: different equity holding in the last age bracket
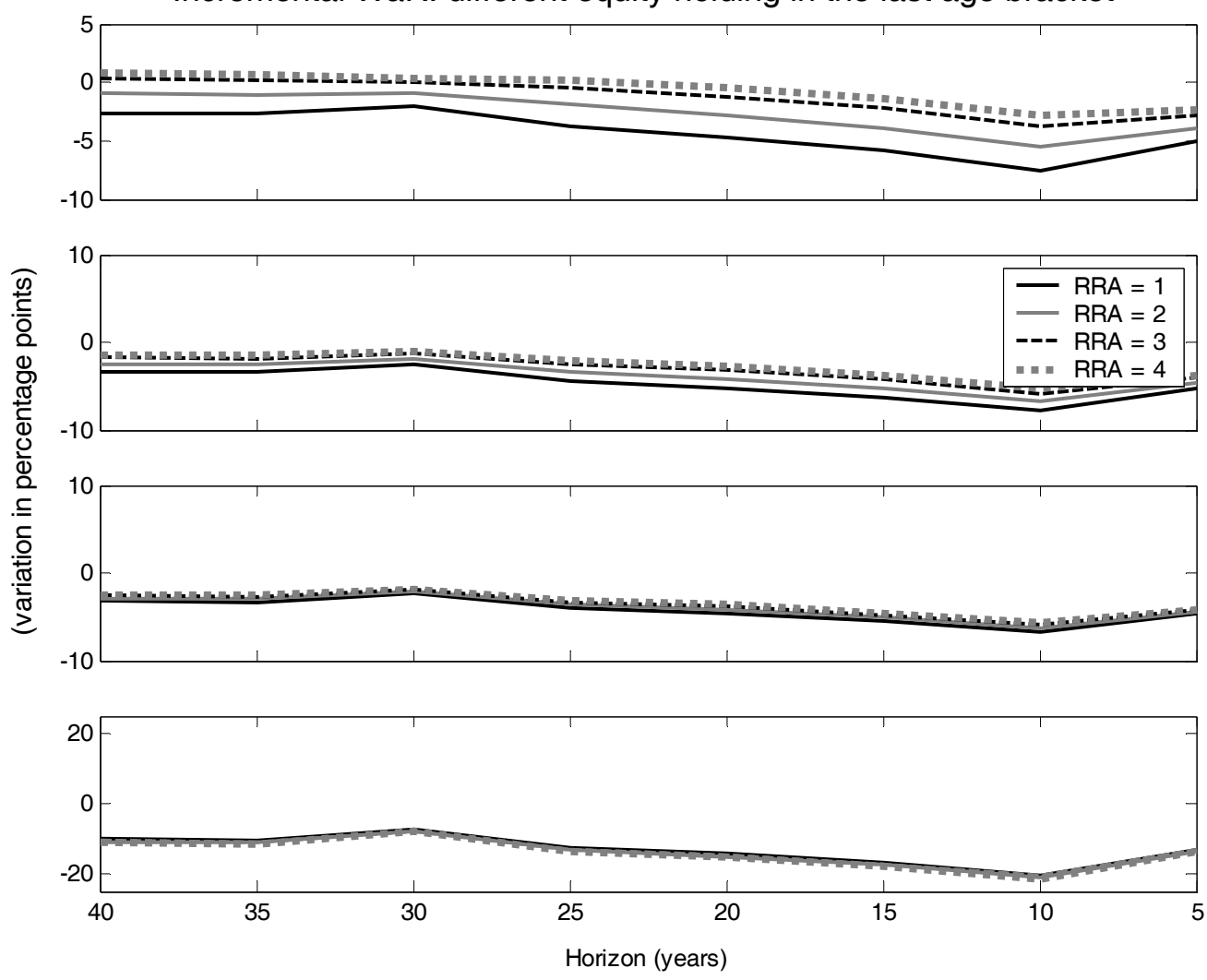
Figure 3

Incremental WaR: different equity holding in the middle age bracket
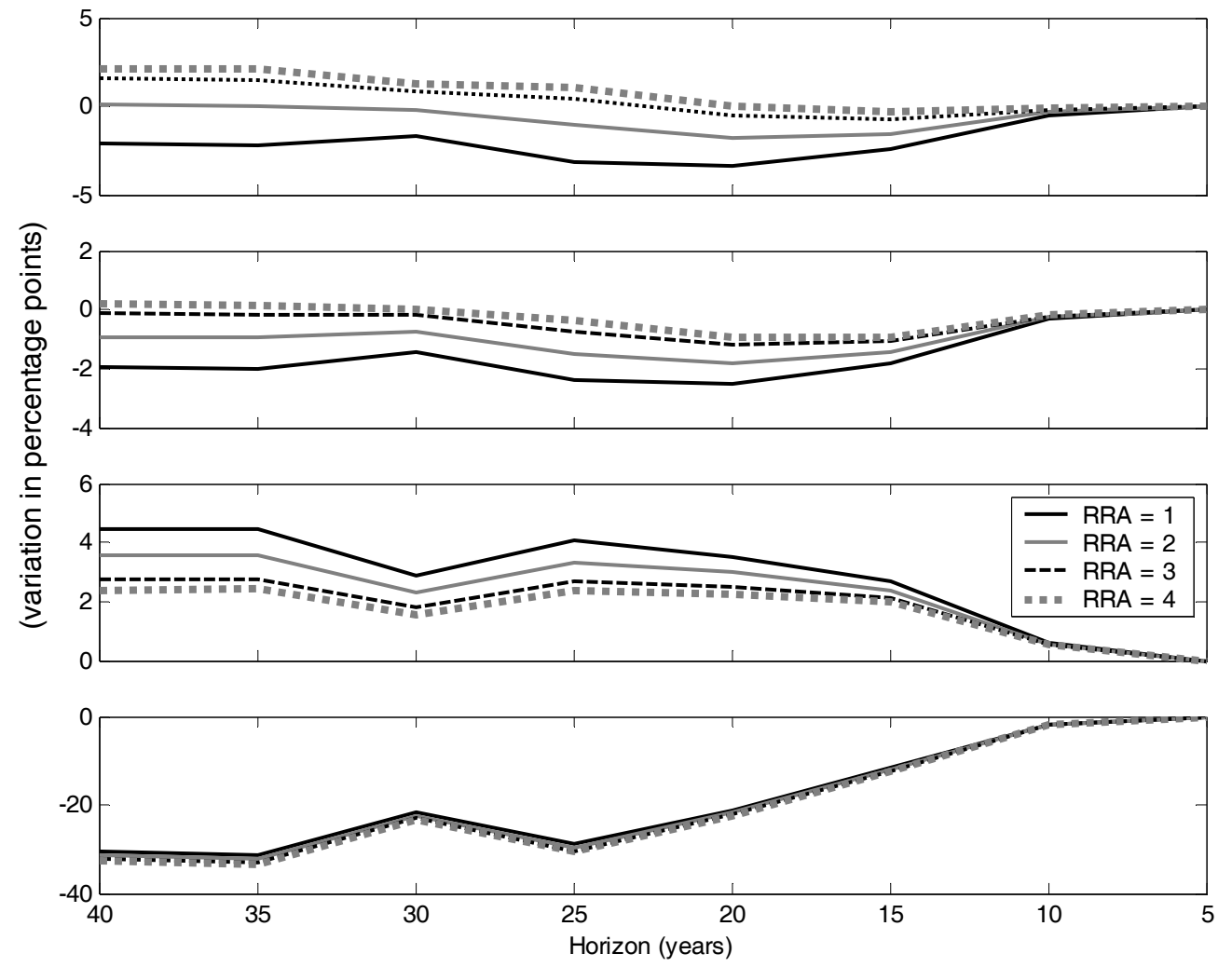
Figure 4

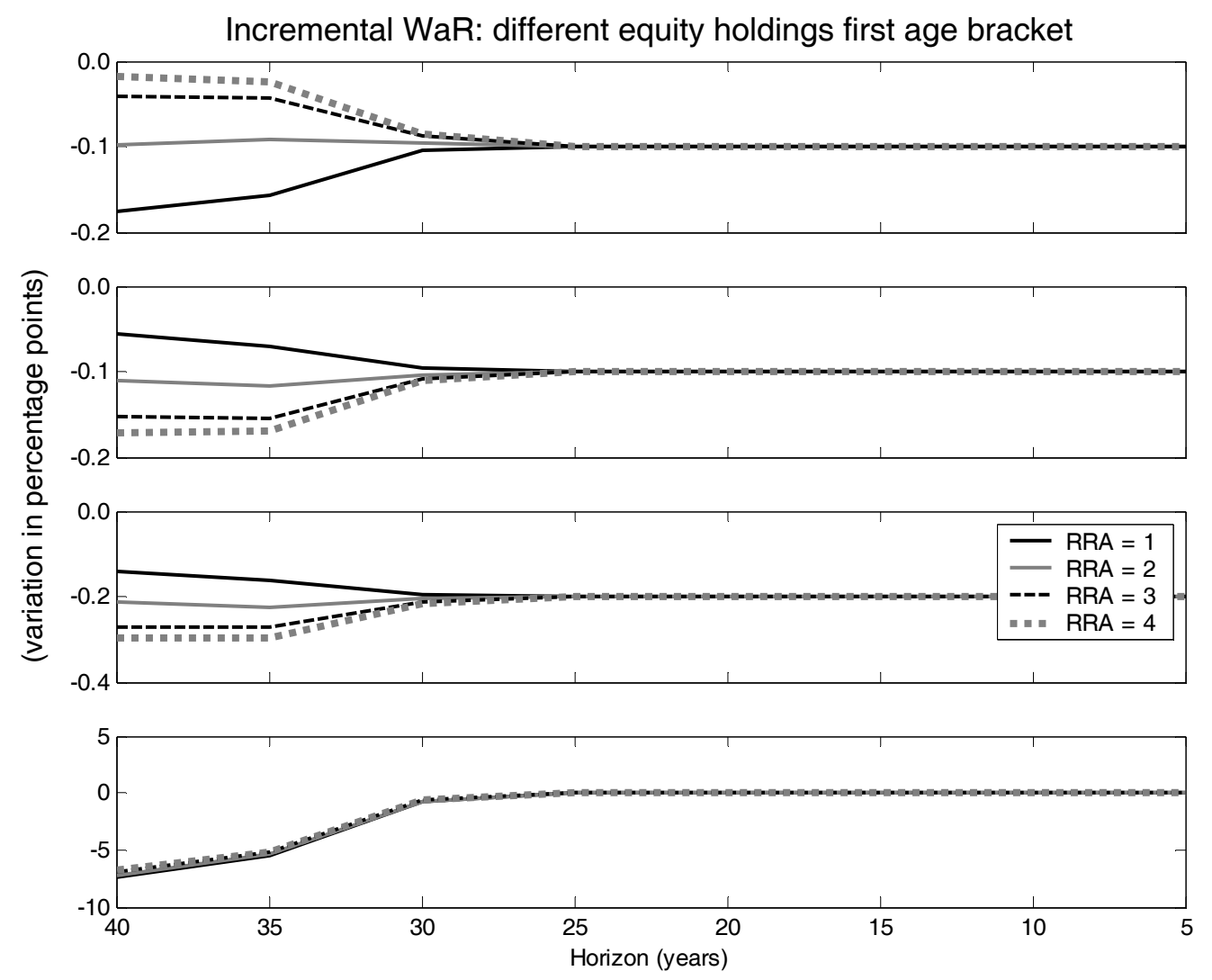




\section{Figure 5}

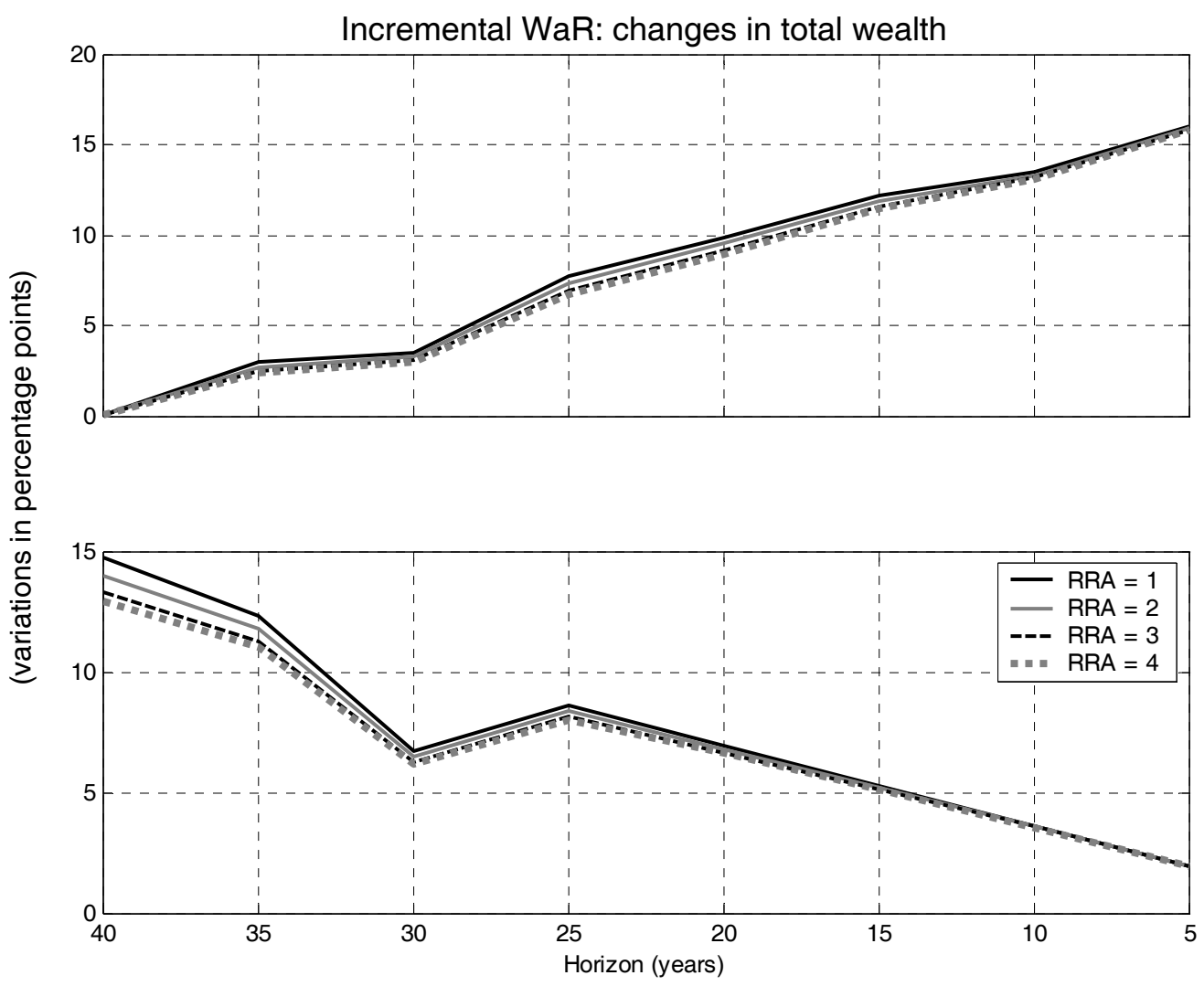


Figure 6

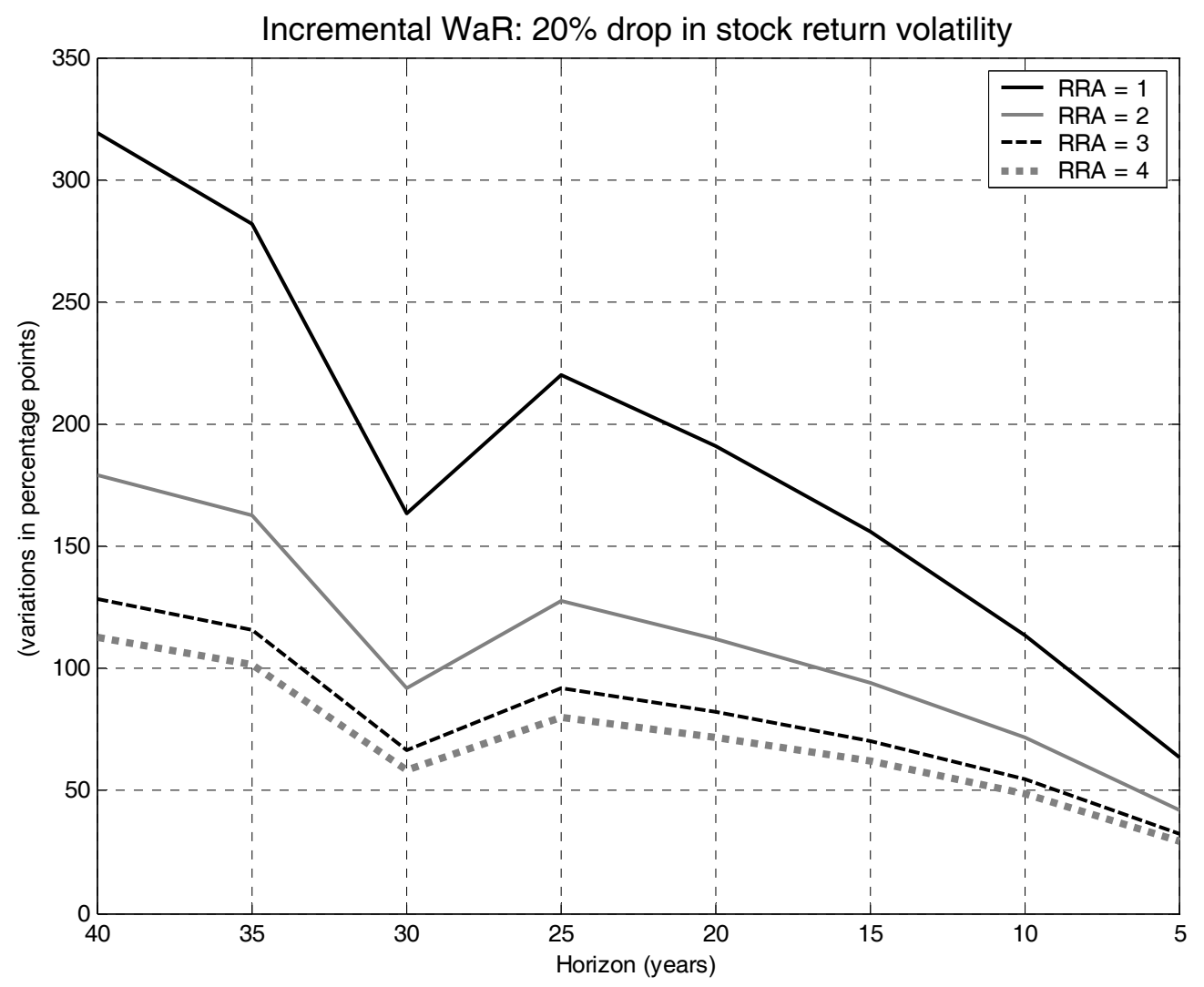

